\title{
Detached shoot treatments cannot replace whole- tree assays when phenotyping for apple resistance to Neonectria ditissima
}

\author{
Reiny W.A. Scheper ${ }^{1, \star}$, Brent M. Fisher ${ }^{1}$, Tara Taylor ${ }^{1}$ and Duncan I. Hedderley ${ }^{2}$ \\ ${ }^{1}$ The New Zealand Institute for Plant \& Food Research Ltd (PFR), Private Bag 1401, Havelock \\ North 4130, New Zealand \\ ${ }^{2}$ PFR, Batchelar Road, Palmerston North 4474, New Zealand \\ *Corresponding author: reiny.scheper@plantandfood.co.nz
}

\begin{abstract}
To develop a fast phenotyping method for European canker resistance of apple, detached-shoot assays were compared with whole-tree phenotyping methods. Disease incidence and lesion length in detached shoots and potted trees of six apple accessions were compared after inoculation with Neonectria ditissima conidia in a glasshouse. Detached shoots were placed in aerated water or in a Chrysal solution, with and without water changes. 'Royal Gala' trees had the highest disease incidence (90\%) and 'Robusta 5' trees remained lesion-free. The treatment-accession interaction effect was significant, with higher disease incidence in detached shoots of 'Robusta 5' (4-32\%) than 'Braeburn' (0-2\%), while 'Braeburn' trees had a high disease incidence (64\%). 'Robusta 5 ' had smaller lesions than the other accessions, but significant differences between accessions were observed on only one of three assessment dates. None of the detached-shoot assays resulted in a similar ranking of the accessions compared with the potted-tree assay, using disease incidence or lesion length. Detached-shoot treatments cannot replace whole-tree assays when phenotyping for European canker resistance of apple.
\end{abstract}

Keywords European canker, Neonectria galligena, Nectria galligena, phenotyping, disease resistance, disease incidence, lesion length, potted trees, detached shoots.

\section{INTRODUCTION}

European canker is a serious disease of apple and pear world-wide. It is caused by the fungus Neonectria ditissima and can result in the death of buds, shoots, spurs and branches (Zeller 1926; Swinburne 1975; Weber 2014). All modern apple cultivars are susceptible to this disease, but they vary in susceptibility (Ghasemkhani et al. 2015a; Ghasemkhani et al. 2015b; Gómez-Cortecero et al. 2016). Recently, a quantitative trait locus (QTL) for a resistance gene to this disease was identified in the crab apple cultivar 'Robusta 5' (V.G.M. Bus, PFR, pers. comm.). Breeding for resistance to European canker will result in easier, cheaper and more sustainable management of tolerant trees, but this is a lengthy process. The use of detached shoots as a fast-phenotyping method rather than whole trees would speed up this process, but in previous research, results of detached-shoot tests have differed from pottedtree tests (Garkava-Gustavsson et al. 2016) and from previously reported field susceptibility (Gómez-Cortecero et al. 2016). In this study, disease development in different detached shoot methods was compared with that in potted trees with the aim to improve the detached shoot test.

\section{MATERIALS AND METHODS}

Plant material

Six accessions were used to compare European canker development in four detached-shoot treatments with that in 1-year-old potted trees. 
The accessions comprised of: four common apple (Malus $x$ domestica) cultivars 'Royal Gala', 'Braeburn', 'Golden Delicious' and 'Sciearly'; a common apple rootstock 'Malling 9' ('M9'; $M$. pumila); and a crab apple 'Robusta 5' (R5; $M$. baccata $\times$ M. prunifolia), which is known to be highly resistant to canker (Gómez-Cortecero et al. 2016; Bus et al. 2017).

The trees were grafted onto 'Merton 793' ('M793'), except for the own-rooted 'M9' rootstock, and were potted into $3.5 \mathrm{~L}$ plastic planter bags (PB6.5). They were maintained in the Hawke's Bay PFR hardstand until 1 September 2017.

Dormant detached shoots of each accession were collected in July-August 2017 from trees that were European canker-free. Those of 'Sciearly' were collected from a commercial orchard block in Hawke's Bay and the remainder from the Hawke's Bay PFR research orchard and stoolbeds, which are European-canker free. The shoots were kept sealed in plastic, in the dark at $1^{\circ} \mathrm{C}$ until 1 September 2017.

\section{Detached shoot treatments}

On 1 September 2017, all dormant detached shoots were cut at a $45^{\circ}$ angle under water, to a length of $1 \mathrm{~m}$. They were placed in a glasshouse in $10 \mathrm{~L}$ plastic buckets with a lid. Six holes (15 $\mathrm{mm}$ diameter) were drilled in each lid, in a 2 $\mathrm{x} 3$ grid, $7 \mathrm{~cm}$ apart, to position six shoots per bucket. One clothes peg per shoot was used to keep the shoots upright.

Shoots were either placed in $5 \mathrm{~L} 0.5 \%$ Chrysal Clear Professional 2 (Chrysal solution, Ghasemkhani et al. 2015a; Ghasemkhani et al. 2015b; Garkava-Gustavsson et al. 2016) or in $5 \mathrm{~L}$ continuously aerated tap water, with or without weekly changes of the Chrysal solution or water. Every week, $5 \mathrm{~mm}$ of the basal part of the shoots in the buckets where the water or the solution was changed was cut at a $45^{\circ}$ angle. The shoots in the buckets without water- or solution-changes were not cut. Mock-inoculated control shoots were placed in $5 \mathrm{~L}$ tap water without aeration or water-changes.

Table 1 Origin of Neonectria ditissima isolates collected in New Zealand that were used to make the inoculum. Isolates that were derived from a single conidium have a " $c$ " after their number; isolates derived from a single ascospore have a " $\mathrm{p}$ " after their number.

\begin{tabular}{lll}
\hline Isolate & Location and year of collection & Host \\
\hline RS 530p & Cambridge, Waikato, 2017 & 'Granny Smith' \\
RS 532p & 'Roybridge, Waikato, 2017 & 'Pink Lady' \\
RS 534p & Cambridge, Waikato, 2017 & 'Fuji Supreme' \\
RS 536p & Cambridge, Waikato, 2017 & 'Scired' \\
RS 540p & Cambridge, Waikato, 2017 & 'Scifresh' \\
RS 552c & Lower Moutere, Tasman, 2017 & 'Cox's Orange' \\
RS 558c & Tasman township, Tasman, 2017 & 'Royal Gala' \\
RS 560p & Redwood Valley, Tasman, 2017 & 'Braeburn' \\
RS 562p & Redwood Valley, Tasman, 2017 & 'Fuji' \\
RS 570c & New Plymouth, Taranaki, 2017 & 'Fuji' \\
RS 571c & New Plymouth, Taranaki, 2017 & 'Scired' \\
RS 574c & New Plymouth, Taranaki, 2017 &
\end{tabular}




\section{Trial design and inoculation}

The five treatments (single-leader potted trees and four detached shoot treatments) were arranged in a glasshouse in an incomplete block design, with five replicates, each comprising 10 bud scars on either two trees or two shoots per accession. An incomplete block design was used to ensure that the detached shoots of the five more-susceptible accessions were placed in the same bucket as the more-resistant R5 the same number of times. Each bucket contained six shoots of three different accessions. Mockinoculated potted trees of each accession, treated with $0.005 \%$ Tween ${ }^{\oplus} 20$ (Tween solution), were placed randomly between the inoculated buckets and trees, as were buckets with mock-inoculated dormant shoots (not included in the analysis).

Inoculum was prepared using conidia grown on Matsushima's medium under continuous near-UV light as described by Scheper et al. (2014). The conidial suspension $\left(7.5 \times 10^{4}\right.$ conidia $\mathrm{mL}^{-1}$ in Tween solution) was prepared by mixing conidia from $12 \mathrm{~N}$. ditissima isolates (Table 1). The conidia were similar to field-collected conidia, with $>75 \%$ of the conidia multi-celled and only $5 \%$ single-celled. The suspension was frozen at $-20^{\circ} \mathrm{C}$ for 1 week (Scheper et al. 2015).

On 1 September 2017, bud scars were made by breaking off the buds on the main leader. Bud scars were at least $15 \mathrm{~cm}$ apart and were marked below the scar with a white paint pen.

On 2 September, the marked scars were artificially inoculated with $20 \mu \mathrm{L}$ conidial suspension using a pipette. The conidial germination rate of the inoculum was determined on glass slides $(60-\mu \mathrm{L}$ droplets) in a humidity chamber on the laboratory bench, after $48 \mathrm{~h}$ of incubation. The germination rate was $78 \%$.

After the inoculation, the relative humidity in the glasshouse was increased to $100 \%$ for 2 days. The temperature in the glasshouse during the inoculation was $19-22^{\circ} \mathrm{C}$. While the humidity was $100 \%$, the temperature dropped to $10^{\circ} \mathrm{C}$ at night and reached $23^{\circ} \mathrm{C}$ during the day. After the 2 -day period of $100 \%$ humidity, the humidity was kept at $75 \%$.

\section{Disease assessments}

The potted trees and detached shoots were assessed three times for the presence of lesions and lesion length, 8, 12 and 16 weeks after inoculation, in October, November and December 2017.

\section{Statistical analysis}

The proportion of inoculated scars with lesions (disease incidence) was analysed using a binomial generalised linear model. The models had fixed effects for replicate, accession, treatment and the accession-treatment interaction. The average lesion length for each replicate of each accessiontreatment combination was log-transformed to stabilise variance and then analysed using unbalanced ANOVA/regression. A factor for replicate was included in all the models. A pairwise t test $(\alpha=0.05)$ was used to determine significant differences between mean lesion lengths.

The ranking of the accessions in each of the detached shoot treatments was compared with that in the potted trees using Spearman's correlation.

Statistical analyses were carried out using Genstat (version 14, 2011, VSNi Ltd, Hemel Hempstead, UK).

\section{RESULTS}

No significant relationship was observed between potted trees and any of the four detached-shoot treatments when comparing the ranking of the accessions using disease incidence at any of the assessment dates $(\mathrm{P}>0.11)$, with Spearman correlations varying between -0.03 and 0.37 .

'Royal Gala' potted trees had the highest disease incidence (90\%) and R5 trees remained lesion-free (Fig. 1A). However, in the detachedshoot treatments, 'M9' had the most lesions when placed in Chrysal solutions and in the aerated water treatment without water changes, and 'Braeburn' remained nearly lesion-free (Fig. 1). The treatment-accession interaction effect was significant at every assessment date $(\mathrm{P}<0.001)$, with higher disease incidence in detached shoots of R5 (4-32\%) than 'Braeburn' 


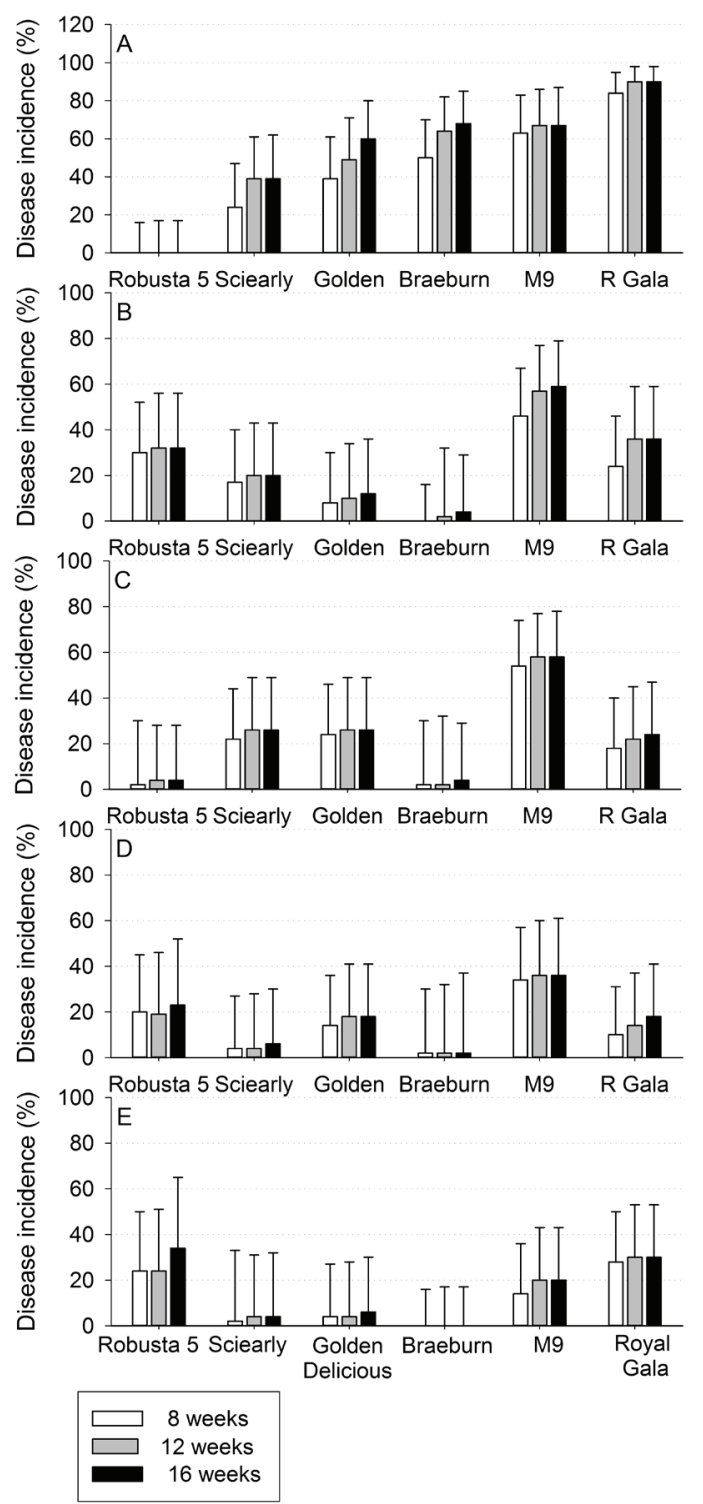

Figure 1 Mean European canker disease incidence (\%) of inoculated apple accessions in 2017, 8-16 weeks after inoculation. One-year-old potted trees (A); detached shoots in Chrysal solution (B); in Chrysal solution with weekly changes of the solution (C); in aerated water (D); and in aerated water with weekly water changes (E). Error bars are $95 \%$ confidence intervals.
$(0-2 \%)$, while 'Braeburn' potted trees had a high disease incidence (64\%). None of the mockinoculated trees or detached shoots developed canker lesions.

As with disease incidence, none of the detached-shoot treatments resulted in scores that were similar to the potted-tree assay, at any of the assessment dates, using lesion length. No significant Spearman correlations between potted trees and the detached shoot treatments were observed, except in the first assessment, when a significant relationship between the ranking of the accessions in potted trees and in aerated water was observed $\left(\mathrm{r}_{\text {Spearman }}=0.81\right)$. However, no linear relationship was observed between lesion size in the same treatments in that assessment $\left(\mathrm{r}_{\text {Pearson }}=0.36, \mathrm{P}=0.49\right)$.

Using lesion length, no treatment-accession interactions were observed, and no significant differences among treatments were observed, except in the first assessment, when potted trees had significantly larger lesions than detached shoots in Chrysal solutions (data not shown). R5 had smaller lesions than the other accessions, but significant differences among accessions were observed only in the second assessment, 12 weeks after inoculation (Table 2).

The detached shoots were more likely to die than the potted trees, with significantly more shoot death in the two aerated-water treatments (31-33\% and $45-61 \%$ after 12 and 16 weeks, respectively) than in the potted trees (5\% and $8 \%$ after 12 and 16 weeks, respectively), while $25 \%$ of detached shoots in the two Chrysal treatments had died after 16 weeks. The treatment-accession interaction effect was significant 12 weeks after inoculation $(\mathrm{P}<0.001)$, with more shoot death in detached shoots of 'Sciearly' in aerated water with water changes $(71 \%)$ and $\mathrm{R} 5$ in both aerated water treatments $(71-81 \%)$ than other accessions in those treatments $(0-39 \%)$, and no death of potted 'Sciearly' and R5 trees.

After 16 weeks, the Chrysal solution in the buckets was cloudy and some had a floating algal mat or some algae on the bottom, while the Chrysal solution that had been changed weekly was clear without any algae. The aerated water 
Table 2 Mean European canker lesion lengths ( $\mathrm{mm}$, back-transformed means) of inoculated apple accessions in 2017, 12 weeks after inoculation. $\mathrm{RG}=$ 'Royal Gala', $\mathrm{Br}=$ 'Braeburn', GD = 'Golden Delicious', Sc = 'Sciearly'. Accessions with the same letter are not significantly different $(\mathrm{P}=0.05)$.

\begin{tabular}{lcccccc}
\hline \multirow{2}{*}{ Treatment } & \multicolumn{7}{c}{ Accession } \\
\cline { 2 - 7 } & RG & $\mathrm{Br}$ & $\mathrm{M} 9$ & $\mathrm{GD}$ & $\mathrm{Sc}$ & $\mathrm{R} 5$ \\
\hline Potted trees & 27 & 19 & 18 & 17 & 10 & $*$ \\
Chrysal solution & 23 & 3 & 36 & 13 & 18 & 5 \\
Chrysal + solution changes & 18 & 5 & 19 & 8 & 9 & 6 \\
Aerated water & 14 & 48 & 27 & 15 & 15 & 3 \\
Aerated + water changes & 18 & $*$ & 11 & 9 & 10 & 3 \\
\hline Mean & $21 \mathrm{a}$ & $14 \mathrm{ab}$ & $22 \mathrm{a}$ & $12 \mathrm{~b}$ & $12 \mathrm{~b}$ & $4 \mathrm{c}$ \\
\hline
\end{tabular}

* No lesions developed

was mainly clear and there were fewer algae on the side and bottom of the buckets when the water had been changed weekly. The water in the negative controls was cloudy with floating algae and algae on the side and the bottom of the buckets. All water was odourless.

\section{DISCUSSION}

To our knowledge, this is the first report of a study where detached shoot methods to determine European canker resistance of apple accessions were compared with a whole-tree assay in the same replicated experiment. In this study, four detached-shoot methods were compared with a potted whole-tree method, and none of the detached-shoot methods resulted in a reliable similar ranking of the accessions as the pottedtree assay.

Significant differences with regard to resistance to European canker were observed among the potted trees when using disease incidence, with 'Royal Gala' the most susceptible while R5 trees remained lesion-free. This result confirms the general understanding that 'Royal Gala' is a susceptible accession and R5 more resistant (Gómez-Cortecero et al. 2016; Amponsah et al. 2017; Bus et al. 2017). Our results also confirmed previous reports of the relative resistance of 'Golden Delicious' (Van de Weg 1989; Ghasemkhani et al. 2015a; GarkavaGustavsson et al. 2016; Gómez-Cortecero et al.
2016; Bus et al. 2017), but the relative resistance of 'Sciearly' potted trees was unexpected, since this accession is known to be more field-susceptible to European canker than 'Royal Gala' in New Zealand (Bus et al. 2017).

Using disease incidence, significant differences among accessions were observed in each of the detached-shoot treatments as well as the potted-tree assay. This suggests that the detached-shoot and potted-tree tests involve different components of resistance and that, for strong resistance, low disease incidence in both tests may be required. However, results from the current study show that resistance in these detached-shoot conditions does not translate into potted-tree resistance. Also, 'Braeburn' was resistant in all detached-shoot assays but it is known to be susceptible to canker in the field.

Detached shoots of R5 had smaller lesions than the other accessions, confirming previous research using detached shoots (GómezCortecero et al. 2016). Garkava-Gustavsson et al. (2013) showed that five apple accessions ranked similarly with regard to lesion length, when assessed as potted trees in the field and detached shoots in a laboratory. However, in a subsequent study, Garkava-Gustavsson et al. (2016) showed an unreliable relationship between colonisation rates in detached shoots in a climate chamber and potted trees in a glasshouse. In the current study, lesion length was not a reliable method 
to rank accessions since significant differences among accessions were observed on only one of the three assessment dates.

Shoot death was a problem in the detachedshoot treatments, as also reported by GarkavaGustavsson (2013); however, in most dead shoots, the presence or absence of canker symptoms was still visible, and few shoots needed to be excluded from the statistical analysis of disease incidence.

Detached-shoot and whole-tree phenotyping methods often result in contradictory resistance classifications, with field-susceptible accessions such as 'Gala' scoring resistant in detached shoot tests (Gómez-Cortecero et al. 2016). Similarly, 'Ákerö’ was highly susceptible in a potted-tree test and more resistant in a detached-shoot test, while detached shoots of 'Elise' were highly susceptible and potted trees of the same accession more resistant (Ghasemkhani et al. 2015b). This study confirms that results from detached-shoot assays need to be treated with caution, and that the detached-shoot methods used in this study cannot replace tree assays when phenotyping for European canker resistance of apple.

\section{ACKNOWLEDGEMENTS}

This work was funded by The New Zealand Institute for Plant \& Food Research Limited. We thank Gagandeep Singla for assistance with plant propagation, Tony Corbett for assistance with the figures, and Dr Vincent Bus, Dr Monika Walter (PFR) and Tim Herman (New Zealand Apples \& Pears) for helpful comments on the manuscript draft.

\section{REFERENCES}

Amponsah NT, Scheper RWA, Fisher B, Walter M, Smits JM, Jesson LK 2017. The effect of wood age on infection by Neonectria ditissima through artificial wounds on different of apple cultivars. New Zealand Plant Protection 70: 97-105.

Bus V, Singla G, Ward S, Brewer L, Morgan C, Bowatte D, Bassett $\mathrm{H}$, Attfield B, Colhoun K, Bastiaanse H, Walter M, Scheper R, Fisher B, Won K, Montanari S, Volz R, Chagné D, Gardiner SE 2017. Progress in pipfruit resistance breeding and research at Plant \& Food Research. Acta Horticulturae 1172: 7-14.

Garkava-Gustavsson L, Ghasemkhani M, Zborowska A, Englund JE, Lateur M, Van de Weg E 2016. Approaches for evaluation of resistance to European canker (Neonectria ditissima) in apple. Acta Horticulturae 1127: 75-81.

Garkava-Gustavsson L, Zborowska A, Sehic J, Rur M, Nybom H, Englund JE, Lateur M, Van der Weg E, Holefors A 2013. Screening of apple cultivars for resistance to European canker, Neonectria ditissima. Acta Horticulturae 976: 529-536.

Ghasemkhani M, Liljeroth E, Sehic J, Zborowska A, Nybom H 2015a. Cut-off shoots method for estimation of partial resistance in apple cultivars to fruit tree canker caused by Neonectria ditissima. Acta Agriculturae Scandinavica Section B-Soil and Plant Science 65: 412-421.

Ghasemkhani M, Sehic J, Ahmadi-Afzadi M, Nybom H, Garkava-Gustavsson L 2015b. Screening for partial resistance to fruit tree canker in apple cultivars. Acta Horticulturae 1099: 687-690.

Gómez-Cortecero A, Saville RJ, Scheper RWA, Bowen JK, De Medeiros HA, Kingsnorth J, Xu XM, Harrison RJ 2016. Variation in host and pathogen in the Neonectria/Malus interaction; toward an understanding of the genetic basis of resistance to European canker. Frontiers in Plant Science 7: 1365.

Scheper RWA, Fisher BM, Amponsah NT, Walter M 2014. Effect of culture medium, light and air circulation on sporulation of Neonectria ditissima. New Zealand Plant Protection 67: 123-132.

Scheper RWA, Frijters L, Fisher BM, Hedderley DI 2015. Effect of freezing of Neonectria ditissima inoculum on its pathogenicity. New Zealand Plant Protection 68: 257-263.

Swinburne TR 1975. European canker of apple (Nectria galligena). Review of Plant Pathology 54: 787-799.

Van de Weg WE 1989. Screening for resistance to 
Nectria galligena Bres. in cut shoots of apple. Euphytica 42: 233-240.

Weber RWS 2014. Biology and control of the apple canker fungus Neonectria ditissima (syn. N. galligena) from a Northwestern European perspective. Erwerbs-Obstbau 56: 95-107.

Zeller SM 1926. European canker of pomaceous fruit trees. Oregon Agricultural College Experimental Station Bulletin 222: 1-52. 